\title{
EFEK BUNGA ES TERHADAP KERJA EVAPORATOR REFRIGERATOR
}

\author{
Akbar Rivan Insanul ${ }^{1 *}$, Widiatmaka F Pambudi ${ }^{2}$, Ndori Akhmad ${ }^{3}$ \\ ${ }^{1,2,3}$ Program Studi Teknika Politeknik Ilmu Pelayaran Semarang \\ Jl. Singosari 2A Semarang \\ *Email: rivaninsanul@gmail.com, pambudi@pip-semarang.ac.id, andori@pip-semarang.ac.id
}

\begin{abstract}
Abstrak
Mesin pendingin ialah rangkaian permesinan bantu untuk menghasilkan suhu dingin. Refrigerator mempunyai 4 komponen utama yaitu Compresor, Condensor, Expansi Valve, dan Evaporator. Refrigerator memiliki peranan yang penting yaitu untuk mengawetkan bahan makanan agar makanan dapat bertahan lebih lama. Metode yang digunakan dalam penelitian ini ialah deskriptif kualitatif dengan teknik analisa data FISHBONE untuk menganalisa masalah dan menentukan strategi. Rumusan masalah dari penelitian adalah faktor penyebab kerja evaporator refrigerator menurun, dampak akibat kerja evaporator refrigerator menurun, upaya yang dilakukan untuk mengatasi kerja evaporator refrigerator menurun. Dari hasil penelitian disimpulkan bahwa penyebab kerja evaporator refrigerator menurun adalah Oil Separator tidak bekerja dengan baik, gangguan pada dryer, penumpukan bunga es pada evaporator, pintu ruangan sering terbuka, dan sistem perawatan dan perbaikan tidak tepat waktu. Dampak yang ditimbulkan yaitu terjadinya minyak lumas masuk dalam sistem, lolosnya kotoran dan air kedalam sistem, menghambat proses penyerapan panas dan penguapan gas freon, banyak udara panas dari luar yang masuk dan timbul masalah baru pada mesin. Upaya yang dilakukan dengan menggunakan FISHBONE yaitu melakukan pembersihan pipa laluan di oil separator, mengganti filter dryer yang baru, melakukan defrosting, meminimalisirkan keluar masuk diruang pendingin dan pembuatan PMS sesuai jadwal dan waktunya sehingga evaporator dapat kembali bekerja dengan optimal dan dapat mencapai suhu yang diinginkan.
\end{abstract}

Kata Kunci :Refrigerator, Evaporator, FISHBONE.

\section{PENDAHULUAN}

Transportasi laut diharapkan bisa cepat, tepat waktu, aman, dan juga selamat. Untuk itu komponen pendukung keseluruhan harus tercukupi dengan baik dan benar. Penunjang kesejahteraan dan kesehatan anak buah kapal adalah merupakan komponen pendukung tersebut. Salah satu penunjang yang sangat vital dan berhubungan dengan kesejahteraan dan kesehatan adalah kualitas dan kuantitas bahan makanan. Bahan makanan itu harus tetap berkualitas meskipun dalam penyimpanan yang lama. Agar bahan makanan itu tidak banyak yang rusak atau busuk. Dengan demikian walaupun kapal berlayar untuk waktu yang cukup lama, kebutuhan akan bahan makanan awak kapal akan cukup tersedia dalam keadaan masih segar dan sehat untuk dikonsumsi. Maka jika kita menggunakan sistem pendinginan untuk bahan makanan, kitatidak perlu khawatirakan kelaparan diatas kapal. Dan bila makanan tercukupi, kita akan punya tenaga dan kemampuan untuk tetap berkarya dengan baik serta kapal tidak perlu berhenti disetiap pelabuhan hanya untuk keperluan bahan makanan dan pada akhirnya akan mengganggu kelancaran profesional kapal dan kerugian pada perusahaan pemilik kapal.

Bahan makanan akan tetap berkualitas walaupun dalam penyimpanan, apabila kita memiliki mesin pendingin yang memenuhi standar kerja. Maka sayur dan buah yang yang dispmpan dalam tempat pendingan akan tetap berkualitas. Sayur dan buah tersebut masih segar, tidak layu atau tidak susut serta rasanya tidak berubah. Untuk daging dan ikan yang masih baik adalah daging dan ikan tersebut tidak lembek, tidak busuk dan saat disimpan dapat membeku seluruhnya dan bila perlu mengkristal. Agar buah dan sayur tetap dalam kondisi baik maka perlu suhu penyimpanan $\pm 2^{\circ} \mathrm{C}$. Untuk penyimpanan daging dan ikan perlu suhu penyimpanan \pm $-18{ }^{\circ} \mathrm{C}$. Pada suhu ini bakteri tidak dapat berkembang biak dan dapat merusak bahan 
makanan seperti pada sayur, buah - buahan, ikan dan daging.

Mesin pendingin memiliki 4 komponen penting yaitu Kompressor, condensor, katup expansi, dan evaporator. Kompresor berfungsi meningkatkan tekanan media pendingin tanpa mengubah bentuk media pendingin tersebut. Dari kompresor media pendingin bertekanan bersuhu tinggi menuju condensor untuk didinginkan dan diubah bentuk dari gas menuju cair tanpa mengubah tekanan media pendingin tersebut. Setelah media pendingin berubah bentuk menjadi cair akan dialirkan menuju expansi, di sini media pendingin akan diubah tekanannya menjadi lebih rendah agar media pendingin dapat berubah wujud menjadi gas kembali. Tempat media pendingin berubah menjadi gas berada di evaporator. Saat media pendingin berubah menjadi gas media pendingin menyerap panas lingkungan. Sehingga temperature suhu sekitar menjadi turun, dan apabila proses ini berlangsung secara terus menerus akan dapat dicapai temperature suhu yang diinginkan.

Namun pada saat proses penyerapan panas lingkungan berlangsung sering terjadi gangguan. Pada tanggal 20 April 2018 di Pelabuhan Kakogawa, Jepang evaporator mengalami timbunan bunga-bunga es yang sangat tebal, dengan adanya bunga - bunga es ini akan sangat mengganggu proses penyerapan panas hingga suhu yang diinginkan tidak dapat tercapai, yang awalnya mampu mencapai suhu $-18^{\circ} \mathrm{C}$ menjadi $0^{\circ} \mathrm{C}$ sampai $+2^{\circ} \mathrm{C}$. Makanan pun menjadi tidak segar, akhirnya cook mengambil tindakan dengan memasak makanan yang ada sebelum membusuk. Dengan kondisi seperti itu kapten memutuskan untuk belanja persediaan makanan, sehingga dana pengeluaran untuk bahan makanan menjadi membengkak. Proses pelayaran juga menjadi terganggu karena kapal harus menambah waktu untuk perbelanjaan makanan.

Melihat dampak yang ditimbulkan dari penggunaan mesin refrigerator yang tidak optimal, maka penulis tertarik untuk melakukan penelitian dengan judul "Penumpukan bunga es menyebabkan kerja evaporator refrigerator menurun di MV. Princess"

Dengan mencermati latar belakang dan judul yang sudah ada, peneliti merumuskan rumusan masalah sebagai berikut:

1.1 Faktor apa yang menyebabkan kerja evaporator refrigerator menurun?

1.2 Dampak apa yang ditimbulkan akibat kerja evaporator refrigerator menurun?

1.3 Upaya apa yang dilakukan untuk mengatasi penyebab kerja evaporator refrigerator menurun?

\section{LANDASAN TEORI}

Menurut Sumanto (2004:2)

"refrigerator adalah suatu pesawat yang menggunakan cairan pendingin untuk mendinginkan ruangan dengan cara menyerap panas yang berada diruangan tersebut (evaporator), sehingga temperaturnya turun sesuai yang dikehendaki". Cara kerja dari sebuah refrigerator dalam sirkulasi proses pendinginan adalah berawal dari kompresor menghisap media pendingin (freon) dari evaporator yang mempunyai tekanan rendah dan bersuhu rendah kemudian dikeluarkan dari kompresor berubah dengan tekanan tinggi dan bersuhu tinggi. Media pendingin akan melalui pemisah minyak atau oil separator, karena media pendingin itu bersifat lebih ringan dari pada minyak maka minyak itu selalu berada dibawah. Minyak dialirkan kembali ke kompresor dari bagian bawah tabung pemisah melalui pipa kecil yang dihubungkan dengan kotak engkol (bagian bawah kompresor). Adanya minyak yang ikut didalam peredaran media pendingin karena disebabkan terjadinya pelumuran atau pelumasan pada kompresor seperti bantalan-bantalan, ring-ring torak dengan silinder. Freon yang telah dipisahkan dari minyak mengalir ke kondensor. Pada bagian kondensor freon didinginkan dengan air laut yang disirkulasikan oleh pompa pendingin. 
Proses pendinginan sejumlah panas diambil oleh freon dari ruang pendingin yaitu disekitar pipa-pipa evaporator. Selanjutnya gas freon dihisap dan dimampatkan kembali oleh kompresor, dan proses berulang kembali. Pada instalasi kapal-kapal modern untuk menghemat tenaga serta mencegah kerusakan maka instalasi tersebut dilengkapi dengan alat kontrol otomatis yang maksudnya untuk memudahkan pengawasan dengan cara yang lebih baik.

Pada refrigerator yang ada sekarang ini, banyak peralatan yang dipasang untuk menunjang kelancaran kerja dan efisiensi dalam pengoperasian maupun penggunaan. Penggunaan peralatan-peralatan tersebut membuat kerja refrigerator semakin optimal. Alat-alat yang ada dalam sistem pendinginan diantaranya adalah : kompresor, kondensor, oil separator, dryer, expantion valve, evaporator dan alat-alat kontrol otomatis. Berikut ini gambar dari instalasi refrigerator yang disertai gambar dari alat-alat dalam sistem pendinginan.

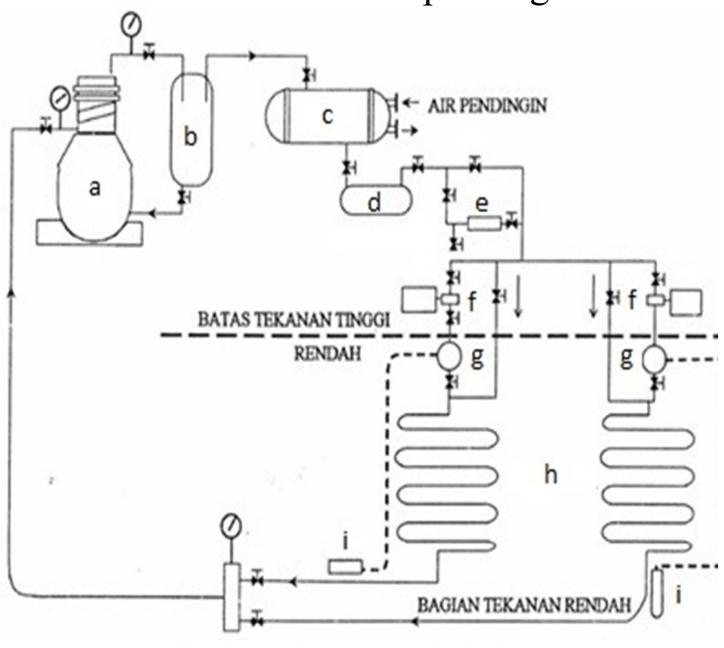

Gambar 1. Instalasi Refrigerator

Keterangan gambar :

$\begin{array}{ll}\text { a. } & \text { Kompressor } \\ \text { b. } & \text { Oil Separator } \\ \text { c. } & \text { Kondensor } \\ \text { d. } & \text { Receiver } \\ \text { e. } & \text { Dryer } \\ \text { f. } & \text { Solenoid Valve } \\ \text { g. } & \text { Expantion Valve } \\ \text { h. } & \text { Evaporator } \\ \text { i. } & \text { Bulb }\end{array}$

Menurut Ega (2013), fungsi dari evaporator adalah untuk menyerap panas dari udara atau benda di dalam ruangan yang diinginkan. Kemudian membuang kalor tersebut melalui kondensor di ruang yang tidak didinginkan.Kompresor yang sedang bekerja menghisap refrigerant gas dari evaporator, sehingga tekanan di dalam evaporator menjadi rendah.Evaporator fungsinya kebalikan dari kondensor.Tidak untuk membuang panas ke udara di sekitarnya, tetapi untuk mengambil panas dari udara di dekatnya.Kondensor ditempatkan di luar ruangan yang sedang didinginkan, sedangkan evaporator ditempatkan di dalam ruangan yang sedang didinginkan.Kondensor tempatnya diantara alat ekpansi dan kompresor, jadi pada sisi tekanan rendah dari sistem.Evaporator dibuat dari bermacam-macam logam, tergantung dari refrigerant yang dipakai dan pemakaian dari evaporator sendiri.

Tiga fungsi utama menurut Whitman, etal (2013), kegunaan evaporator adalah untuk menyerap panas dari media yang didinginkan, memungkinkan panas mendidih dari refrigerant cair menjadi refrigerant uap ditabungnya, dan memungkinkan panas untuk super heat uap refrigerantnya di dalam bagian tabungnya.

Guna mempermudah penyusunan analisis penelitian ini, digunakan kerangka pemikiran yang secara sistematis seperti gambar berikut :

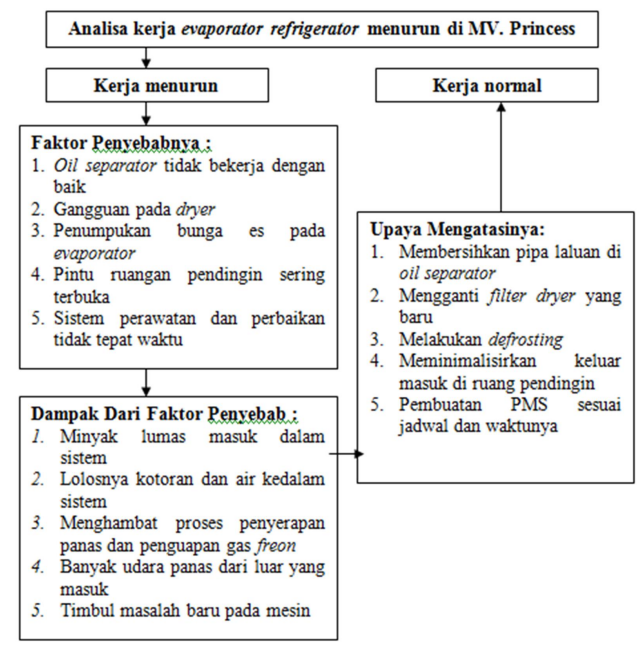

Gambar 2. Kerangka Pikir Penelitian 


\section{METODE}

Metode penelitian yang digunakan oleh penulis adalah metodologi penelitian diskriptif kualitatif. Metode ini digunakan untuk menggambarkan dan menguraikan objek yang diteliti serta kaidah-kaidah yang diambil dari teori-teori yang berhubungan dengan topik yang dibahas, selain itu juga menggunakan pendekatan di lapangan yang telah dilaksanakan selama praktek laut dengan cara mengamati dan terjun langsung dalam perawatan, perbaikan dan keselamatan pada mesin refrigerator demi kelancaran operasional kapal selama pelayaran.

Di dalam pembahasan penulis akan berusaha memaparkan hasil dari semua studi dan penelitian mengenai suatu objek yang diperoleh, baik hal-hal yang bersifat teori maupun memuat hal-hal yang bersifat praktis, dalam artian bahwa selain ditulis dari beberapa literatur buku, juga bersumber dari objek-objek penelitian yang juga terdapat dalam buku kemaritiman. Penggunaan aspek observasi atau pengamatan sangat berperan dalam penulisan skripsi.

Penelitian tentang kerja evaporator refrigerator menurun dilakukan selama praktek laut berlangsung, yaitu terhitung mulai tanggal 10 November 2017 sampai dengan tanggal 12 November 2018. Penelitian ini dilakukan di atas kapal MV. PRINCESS. Kapal ini merupakan salah satu kapal general cargo milik SHL MARITIME Co. Ltd.

Jenis data dalam kajian ini data primer dan sekunder. Data Primer diperoleh secara langsung dari sumber pertamanya melalui hasil wawancara, diamati dan dicatat gejala-gejala yang tampak pada objek penelitian. Data primer dalam menentukan ini berupa pengamatan dan hasil wawancara tentang kerja refrigerator di MV. PRINCESS. Penulis memperoleh data dari hasil wawancara dengan perwira mesin tentang kerja evaporator refrigerator menurun di MV.PRINCESS. Data sekunder diperoleh dari log book dengan objek penelitian skripsi atau yang berhubungan dengan permasalahan yang akan dibahas, yang diperlukan sebagai pedoman teoritis dan kententuan formal dari keadaan formal dari keadaan nyata dalam observasi, serta dari informasi lain yang telah disampaikan pada saat kuliah.

Pengumpulan data dilakukan melalui obeservasi secara langsung selama praktek laut di atas kapal tentang kerja evaporator refrigerator menurun di kapal MV. PRINCESS. Penemuan masalah kerja evaporator refrigerator menurun yang disebabkan oleh berbagai macam hal yang ditemukan pada saat pelaksanaan praktek laut. Selain itu, penulis melakukan wawancara secara langsung terhadap obyek penelitian dalam hal ini para perwira mesin dikapal. Disini penulis bertanya tentang masalah-masalah obyek yang diteliti baik itu mengenai cara pengoprasian,perawatan maupun cara mengatasi masalah yang terjadi pada refrigerator dengan baik dan benar.

Dokumentasi merupakan salah satu teknik pengumpulan data yang digunakan oleh penulis dengan mencatat dan mengambil gambar bagian-bagian mesin serta saat mengerjakan perbaikan dan perawatan terhadap suatu permesinan dan segala sesuatu yang berhubungan dengan refrigerator dan sistemnya. Dalam teknik ini, arsip serta dokumen-dokumen kapal digunakan untuk melengkapi data yang diperoleh, sehingga data tersebut bisa lebih akurat dan dapat dipertanggung jawabkan.

Analisis data menggunakan metode Fishbone. Fishbone adalah salah satu metode/ tool didalam meningkatkan kualitas, sering juga diagram ini disebut dengan diagram sebab-akibat atau cause effect diagram.

Penerapan diagram fishbone (tulang Ikan) cause and effect (sebab dan akibat) Ishikawa ini dapat menolong kita untuk dapat menemukan akar "penyebab" terjadinya masalah khususnya di atas kapal dimana proses kapal terkenal dengan banyaknya ragam variabel yang berpotensi menyebabkan munculnya permasalahan. Apabila "masalah" dan "penyebab" sudah 
diketahui secara pasti, maka tindakan dan langkah perbaikan akan lebih mudah dilakukan.

\section{HASIL DAN PEMBAHASAN}

\section{Gambaran umum objek penelitian}

Obyek penelitian adalah evaporator refrigerator yang ada di kapal MV. Princess seperti spesifikasi refrigerator, cara kerja refrigerator dan cara perawatan dan perbaikan refrigerator

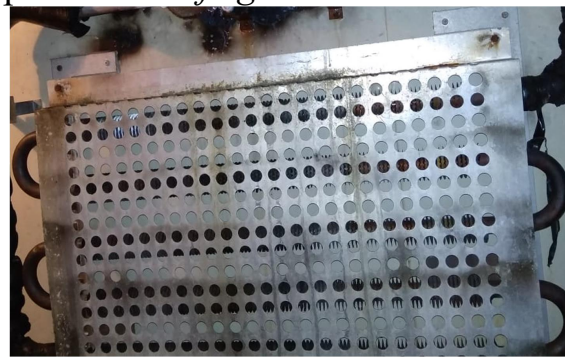

Gambar 3. Evaporator Refrigerator

Spesifikasi refrigerator

Data dari mesin pendingin yang ada di kapal MV. PRINCESS adalah :

Refrigerating machine unit : Self Provision Unit URS-3

OSSSD $\times 2$ Sets

Refrigerant: $R-22$

Power source: $A C 440 \mathrm{~V} 60 \mathrm{~Hz} 3 \varnothing$

Compressor: FA-2MSYM

Type: Semi hermetic multicylinder

Cyl diameter $x$ stroke $x$ : ø $50 \mathrm{~mm} \times 40 \mathrm{~mm}$ $x 2$ Cylcount

Drivesystem $x$ Revolution: Direct start $x$ $1750 \mathrm{rpm}$

Compressor motor type: Enclose type induction motor

Polecount $x$ Revolution: 4 P x $1750 \mathrm{rpm}$

Evaporator Meat\&: UNIT COOLER CM U151UHA

Fish Room Type

Material: Copperpipewith

Coolingcapacity: About 1988 WS About

$$
1710 \mathrm{kcal} / \mathrm{h}
$$

Fan: $A C 100 \mathrm{~V} 50 \mathrm{~W} 29.8 \mathrm{~m}^{3} \mathrm{~min}$

Oil separator: M301404

Type: Vertical, Auto oilreturn

Shall diameter $x$ lenght: $130 \emptyset \times 300 \mathrm{~mm}$

Type: Vertical, Drip proof

Maker: USHIO REINETSU CO. LTD

Coolingsystem:

$R-22$

Directexpansionsystem
Dalam sirkulasi mesin pendingin terdapat proses kompresi, kondensasi, ekspansi dan evaporasi. Proses kompresi terjadi pada refrigerant yang berwujud gas akan dimampatkan oleh kompresor. Proses kondensasi terjadi saat refrigerant yang berwujud gas melewati kondensor untuk didinginkan dan berubah wujud menjadi cair. Proses ekspansi terjadi saat refrigerant yang berwujud cair bertekanan dan bersuhu tinggi melewati katup ekspansi sehingga refrigerant akan berubah wujud menjadi mist refrigerant (kabut) dan bersuhu rendah untuk disemburkan. Proses evaporasi terjadi pada refrigerant yang akan menguap pada pipa-pipa coil evaporator.

Dari penjelasan proses tersebut diatas, dimana terjadi proses penguapan di pipapipa coil evaporator yang akan dimanfaatkan untuk mendinginkan suatu ruangan. Saat refrigerant dalam pipa-pipa evaporator menguap, menyerap panas disekitar pipa-pipa coil evaporator, sehingga ruangan pendingin menjadi lebih dingin. Karena proses pengupan terjadi terus-menerus dan berlangsung sangat cepat maka keadaan ruang pendingin menjadi semakin dingin. Dengan keberadaan blower yang dipasang dekat pipa-pipa coil evaporator, udara dingin tersebut dihembuskan keseluruh ruangan pendingin sehingga menjadi semakin dingin.

Tabel 1. Program Perawatan dan Perbaikan Refrigerator

\begin{tabular}{|c|c|c|c|c|}
\hline No & $\begin{array}{c}\text { Waktu } \\
\text { Pengece } \\
\text { kan }\end{array}$ & $\begin{array}{c}\text { Jenis } \\
\text { Pengecekan }\end{array}$ & $\begin{array}{c}\text { Titik } \\
\text { Pengecek } \\
\text { an }\end{array}$ & $\begin{array}{c}\text { Standar } \\
\text { Penyetel } \\
\text { an }\end{array}$ \\
\hline \multirow[t]{4}{*}{1} & \multirow[t]{4}{*}{$\begin{array}{l}\text { Setiap } \\
\text { Hari }\end{array}$} & $\begin{array}{c}\text { Minyak } \\
\text { Lumas } \\
\text { Kompresor }\end{array}$ & $\begin{array}{c}\text { Jumlahny } \\
\text { a }\end{array}$ & $\begin{array}{l}1 / 2 \text { dari } \\
\text { gelas } \\
\text { duga dan } \\
\text { oli tidak } \\
\text { kotor } \\
\end{array}$ \\
\hline & & $\begin{array}{l}\text { Tekanan } \\
\text { minyak } \\
\text { lumas }\end{array}$ & $\begin{array}{c}\text { Tekanan } \\
\text { pada } \\
\text { manomet } \\
\text { er-nya }\end{array}$ & $\begin{array}{c}3-5 \\
\mathrm{~kg} / \mathrm{cm}^{2}\end{array}$ \\
\hline & & $\begin{array}{c}\text { Temperatur } \\
\text { Air } \\
\text { pendingin } \\
\text { kondensor }\end{array}$ & $\begin{array}{c}\text { Lihat } \\
\text { Thermme } \\
\text { ter-nya }\end{array}$ & $\begin{array}{c}\text { Perbedaa } \\
\text { n suhu } \\
\text { air } \\
\text { masuk } \\
\text { dan } \\
\text { keluar 3- } \\
5^{\circ} \mathrm{C}\end{array}$ \\
\hline & & $\begin{array}{c}\text { Getaran } \\
\text { dan }\end{array}$ & $\begin{array}{c}\text { Getaran } \\
\text { dan suara }\end{array}$ & $\begin{array}{c}\text { Jangan } \\
\text { ada }\end{array}$ \\
\hline
\end{tabular}




\begin{tabular}{|c|c|c|c|c|}
\hline & & Suaranya & $\begin{array}{l}\text { yang } \\
\text { terjadi }\end{array}$ & $\begin{array}{c}\text { getaran } \\
\text { dan suara } \\
\text { yang } \\
\text { berlebih }\end{array}$ \\
\hline & & $\begin{array}{c}\text { Cek bunga } \\
\text { es di pipe } \\
\text { line }\end{array}$ & $\begin{array}{c}\text { Pipa-pipa } \\
\text { di tekanan } \\
\text { rendah }\end{array}$ & $\begin{array}{c}\text { Melakuk } \\
\text { an } \\
\text { defrostin } \\
\mathrm{g}\end{array}$ \\
\hline \multirow[t]{4}{*}{2} & \multirow[t]{4}{*}{$\begin{array}{c}\text { Setiap } 3 \\
\text { Bulan }\end{array}$} & $\begin{array}{c}\text { Ganti Filter } \\
\text { dryer }\end{array}$ & $\begin{array}{c}\text { Cek } \\
\text { kondisi } \\
\text { filter } \\
\text { dryer }\end{array}$ & $\begin{array}{c}\text { Sesuai } \\
\text { spesifika } \\
\text { si }\end{array}$ \\
\hline & & $\begin{array}{c}\text { Bersihkan } \\
\text { oil } \\
\text { separator }\end{array}$ & $\begin{array}{c}\text { Cek } \\
\text { laluan } \\
\text { minyak } \\
\text { lumas }\end{array}$ & $\begin{array}{c}\text { Bersihka } \\
\mathrm{n} \text { dan } \\
\text { tidak } \\
\text { buntu }\end{array}$ \\
\hline & & $\begin{array}{l}\text { Bersihkan } \\
\text { kondensor }\end{array}$ & $\begin{array}{c}\text { Buka } \\
\text { cover } \\
\text { kondenso } \\
\mathrm{r}\end{array}$ & $\begin{array}{c}\text { Bersih } \\
\text { dan tidak } \\
\text { buntu }\end{array}$ \\
\hline & & $\begin{array}{c}\text { Cek anti } \\
\text { korosinya }\end{array}$ & $\begin{array}{c}\text { Periksan } \\
\text { pengurun } \\
\text { gan } \\
\text { potongan } \\
\text { anti } \\
\text { korosi }\end{array}$ & $\begin{array}{c}\text { Ganti } \\
\text { jika } \\
\text { pengurun } \\
\text { gan } \\
\text { menjadi } \\
1 / 3 \\
\text { ketebala } \\
n\end{array}$ \\
\hline \multirow[t]{4}{*}{3} & \multirow[t]{4}{*}{$\begin{array}{c}\text { Setiap 1 } \\
\text { Tahun }\end{array}$} & $\begin{array}{l}\text { Cek high } \\
\text { pressure } \\
\text { switch }\end{array}$ & $\begin{array}{l}\text { Penyetela } \\
\text { n high } \\
\text { pressure } \\
\text { switch }\end{array}$ & $\begin{array}{c}\text { Penyetel } \\
\text { an } \\
\text { tekanan } \\
=0.01 \\
\text { Mpa }\end{array}$ \\
\hline & & $\begin{array}{l}\text { Cek low } \\
\text { pressure } \\
\text { switch }\end{array}$ & $\begin{array}{c}\text { Penyetela } \\
\text { n low } \\
\text { pressure } \\
\text { switch }\end{array}$ & $\begin{array}{c}\text { Penyetel } \\
\text { an } \\
\text { tekanan } \\
=0.02 \\
\text { Mpa }\end{array}$ \\
\hline & & $\begin{array}{c}\text { Sistem } \\
\text { pelumasan } \\
\text { kompresor }\end{array}$ & $\begin{array}{c}\text { Cek pada } \\
\text { gelas } \\
\text { duga }\end{array}$ & $\begin{array}{c}\text { Ganti oli } \\
\text { baru }\end{array}$ \\
\hline & & $\begin{array}{l}\text { Over haul } \\
\text { kompresor }\end{array}$ & $\begin{array}{l}\text { Lakukan } \\
\text { pengukur } \\
\text { an } \\
\text { clereance }\end{array}$ & $\begin{array}{c}\text { Sesuai } \\
\text { standart }\end{array}$ \\
\hline
\end{tabular}

Pada kenyataannya mesin pendingin di atas kapal tidak selalu bekerja dengan optimal, karena hal ini dipengaruhi oleh banyak faktor, baik faktor internal dan eksternal. Seperti yang terjadi di kapal MV.PRINCESS pada saat itu kapal berada di pelabuhan Kakogawa Jepang terjadi kenaikan temprature yang drastis pada ruangan daging dan ikan mencapai temprature $10^{\circ} \mathrm{C}$ yang seharusnya $-180{ }^{\circ} \mathrm{C}$ dan temprature pada ruangan sayur dan buah $120^{\circ} \mathrm{C}$ yang seharusnya $20^{\circ} \mathrm{C}$. Berikut adalah hasil perbandingan antara keadaan pada manual book dengan hasil pengukuran suhu pada masing-masing ruangan yang diisi di log book pada saat kerja evaporator refrigerator menurun.

\section{Analisa Permasalahan}

Faktor-faktor yang menyebabkan kerja evaporator refrigerator menurun adalah faktor mesin, lingkungan, manusia dan prosedur.

\section{a. Faktor mesin}

Faktor mesin yang menyebabkan turunnya kinerja evaporator refrigerator adalah Oil Separator tidak bekerja dengan baik, dan adanya gangguan pada dryer.

Berdasarkan observasi penulis, Oil Separator tidak bekerja dengan baik diakibatkan oleh tersumbatnya lubang laluan untuk kembalinya minyak lumas ke dalam ruang engkol compressor sehingga mengakibatkan minyak lumas yang ada di Oil Separator akan penuh dan minyak lumas tersebut akan ikut masuk ke dalam sistem. Karena hal itu minyak lumas akan masuk ke dalam sistem dan membentuk partikel-partikel dan bunga es di pipa coil evaporator akan mengakibatkan kerja evaporator refrigerator menurun.

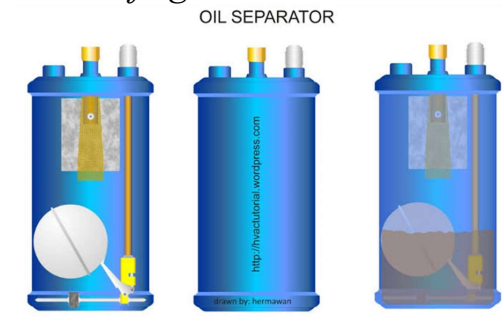

\section{Gambar 4. Laluan Minyak Lumas di Oil} Separator

Gangguan pada dryer sering terjadi pada mesin pendingin yang mengalami kelainan pada sistem kerjanya. Pada umumnya gangguan yang terjadi pada filter adalah penyumbatan terhadap saringan kasa halus oleh kerak-kerak akibat korosi, gramgram akibat keausan silinder, piston dan ring piston kompresor. Disamping kotoran tersebut tersumbatnya saringan kasa halus juga disebabkan karena busa minyak pelumas yang membeku didalam saringan. 


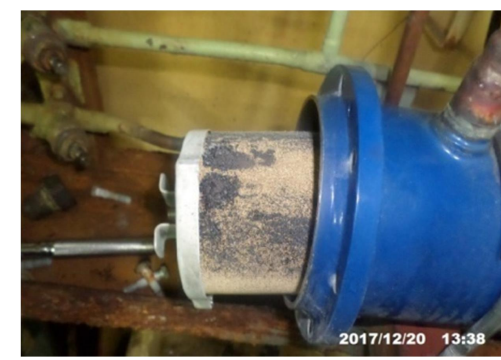

Gambar 5. Filter Dryer hancur

\section{b. Faktor lingkungan}

Penumpukan bunga es di pipa coil evaporator menyebabkan kinerja evaporator refrigerator juga tururn. Berdasarkan observasi penulis evaporator dapat bekerja dengan baik jika line pipa coil evaporator tidak ada kotoran di dalamnya dan bunga es di luarnya, karena jika adanya bunga es di pipa line pipa coil evaporator akan menghambat proses penyerapan panas dan penguapan zat pendingin, tetapi yang terjadi di kapal adalah pipa coil evaporator mengalami penumpukan bunga es yang disebabkan oleh lolosnya kotoran dan air kedalam system dan pembersihkan bunga es di pipa coil evaporator tidak tepat waktu.

\section{c. Faktor manusia}

Kesalahan manusia yang menyebabkan turunnya kinerja evaporator generator adalah membiarkan pintu ruangan pendingin terbuka.

Tiap kali membuka pintu ruangan dingin maka udara dingin dalam ruangan dingin yang berat jenisnya lebih besar akan keluar, tempat yang kosong dan vacuum akan diisi udara dari luar yang panas, maka suhu di ruangan pendingin akan naik. Udara yang masuk di ruangan pendingin akan diserap kandungan panasnya oleh pipa coil evaporator, sehingga semakin udara luar yang masuk ke ruangan semakin banyak pula kandungan panas yang terdapat didalam udara diserap coil evaporator.

\section{d. Faktor prosedur}

Sistem perawatan dan perbaikan tidak tepat waktu juga dapat menyebabkan kinerja evaporator generator turun. Dalam pengoperasian suatu permesinan diatas kapal diperlukan suatu sistem yang mengatur tentang perawatan dan pemeliharaan bagian-bagian utama pada permesinan tersebut. Hal ini diperlukan untuk menghindari terjadinya masalah yang dapat menghambat kerja dari mesin tersebut. Selain itu sistem pemeliharaan yang dilakukakan secara terencana dan berkala, juga dapat memperpanjang usia pakai suatu kapal sehingga dapat menambah produktifitas kapal tersebut.

\section{Pembahasan Masalah}

Dalam pembahasan permasalahan yang terjadi di MV. PRINCESS penulis menggunakan metode fishbone analysis untuk mencari faktor-faktor yang kemungkinan dapat menyebabkan kerja evaporator refrigerator menurun. Mencari penyebab masalah dengan menarik seluruhan alisa dari tiap sebab kedalam sub sebab sehingga permasalahan paling mendasar terselesaikan, dari hal ini dapat diketahui bagian mana dari sistem yang gagal dan perlu dilakukan tindakan serta pencegahan berdasarkan kegagalan yang ada agar kejadian yang sama tidak terulang.

Tabel 2. Garis Besar Isi Permasalahan Dalam Diagram Fisbhone

\begin{tabular}{|c|c|}
\hline Faktor yang diamati & Masalah yang terjadi \\
\hline 1. Machine & $\begin{array}{ll}\text { - Oil Separator } \\
\text { tidak Bekerja } \\
\text { - Gangguan pada } \\
\text { dryer }\end{array}$ \\
\hline 2. Environment & 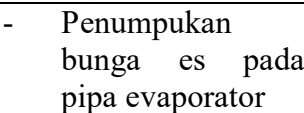 \\
\hline 3. Man & $\begin{array}{llr} & \text { Pintu ruangan } \\
\text { pendingin } & \text { sering } \\
\text { terbuka } & \end{array}$ \\
\hline 4. Method & $\begin{array}{llr}\text { - } & \text { Perawatan dan } \\
\text { perbaikan } & \text { tidak } \\
\text { tepat waktu } & \end{array}$ \\
\hline
\end{tabular}

permasalahan yang terjadi. Faktor yang diamati berupa mesin, lingkungan, manusia dan metode digunakan sebagai sebab dan pada bagian masalah yang terjadi di aplikasikan sebagai cabang duri dari penyebab timbulnya permasalahan tersebut pada fishbone diagram disebut dengan sub bab. Pada tiap sub bab yang ada merupakan bentuk pendekatan masalah diatas kapal, bentuk pendekatan yang diambil oleh 
penulis merupakan bentuk pemikiran, kemungkinan penyebab terjadinya permasalahan yang terjadi.

Dengan menganalisa dan mereduksi data serta berdasarkan sumber literatur dan wawancara diharapkanakan menemukan suatu pokok permasalahan. Permasalahan tersebut dapat disusun sebagaimana pada diagram fishbone berikut :

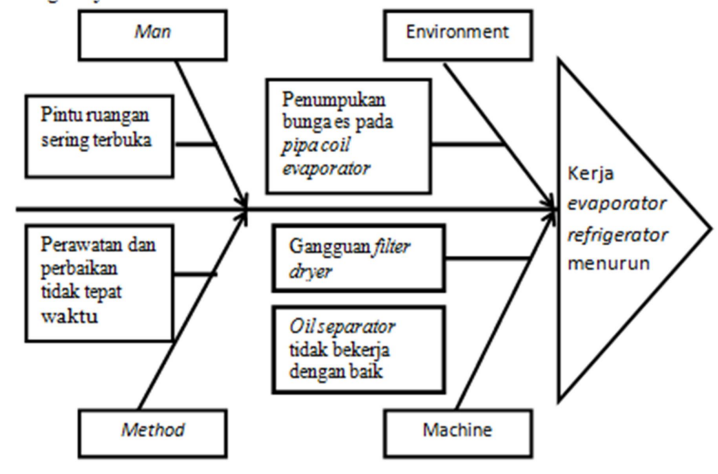

Gambar 6 Diagram Fishbone

\section{a. Faktor mesin}

Tersumbatnya lubang laluan untuk kembalinya minyak lumas kedalam ruang engkol compressor akan membuat Oil Separator tidak bekerja dengan baik, tersumbatnya lubang itu terjadi dikarenakan kurangnya perawatan atau pembersihkan Oil Separator sehingga minyak lumas menumpuk dan membuat partikel-partikel yang menyebabkan penyumbatan. Dampak dari penyumbatan itu mengakibatkan minyak lumas yang ada di oilseparator akan penuh dan minyak lumas tersebut akan ikut masuk ke dalam sistem. Karena hal itu minyak lumas akan masuk ke dalam sistem dan membentuk partikel-partikel dan bunga es di pipa coil evaporator akan mengakibatkan kerja evaporator refrigerator menurun.

Dari faktor masalah serta dampak yang ditimbulkan dari masalah Oil Separator tidak bekerja dengan baik terdapat upaya untuk mengatasi masalah tersebut, upaya yang dilakukan adalah membersihkan pipa laluan minyak lumas kembali ke ruang engkol compressor sesuai dengan jadwal perawatan dan perbaikan yang ada di manual book.
Kondisi gangguan pada dryer adalah salah satu penyebab dari faktor menurunnya kerja evaporator refrigerator, pada umumnya gangguan yang terjadi adalah pada bagian filter yaitu penyumbatan terhadap saringan kasa halus oleh kerakkerak akibat korosi, gram-gram akibat keausan silinder, piston dan ring piston kompresor. Disamping kotoran tersebut tersumbatnya saringan kasa halus juga disebabkan karena busa minyak pelumas yang membeku didalam saringan, dampak dari gangguan dryer itu sendiri yaitu lolosnya kotoran dan air kedalam sistem yang mengakibatkan terjadinya bunga es pada pipa coil evaporator, gangguan pada dryer disebabkan filter dryer yang sudah lama tidak di ganti.Upaya yang dilakukan adalah mengganti filter dryer dengan yang baru.

\section{b. Faktor lingkungan}

Salah satu faktor masalah menurunnya kerja evaporator refrigerator adalah terjadinya penumpukan bunga es di pipa coil evaporator yang disebabkan oleh masuk nya udara luar atau adanya kotoran dan air yang masuk kedalam pipa coil evaporator, yang berdampak terjadinya bunga es di pipa line pipa coil evaporator yang akan menghambat proses penyerapan panas dan penguapan zat pendingin.

Upaya yang dilakukan adalah melakukan pumping down, defrosting dan pembersihan pada pipa coil evaporator serta memperbaiki komponen lain yang bermasalah.

\section{c. Faktor manusia}

Manusia adalah yang paling berperan dalam terjadinya kejadian ini, dikarenakan koki yang sering membuka tutup pintu ruangan pendingin sehingga udara dingin dalam ruangan pendingin yang berat jenisnya lebih besar akan keluar dan tempat kosong di dalam ruangan pendingin akan diisi udara dari luar yang panas, sehingga diserap oleh pipa coil evaporator, dampaknya akan mengakibatkan terjadinya bunga-bunga es didalam ruangan 
pendingin, sehingga akan menghambat proses penyerapan panas dan penguapan zat pendingin pada pipa coil evaporator.

Upaya yang dilakukan memberi pengetahuan tentang refrigerator dan efek dari sering terbuka nya pintu pendingin kepada koki, setelah itu untuk meminimalisirkan pintu sering terbuka usahakan koki telah membuat daftar bahanbahan makanan yang akan diambil di ruangan pendingin sehingga tidak terlalu sering keluar masuk ruangan pendingin.

\section{d. Faktor prosedur}

Sistem perawatan dan perbaikan tidak tepat waktu Salah satu contoh kesalahan dalam faktor prosedur adalah sistem perawatan dan perbaikan tidak tepat waktu, yang berdampak buruk pada komponenkomponen dipermesinan mesin pendingin makanan, Upaya yang dilakukan untuk mengatasi perawatan dan perbaikan tidak tepat waktu adalah dengan memberikan peringatan jadwal perawatan sesuai manual book baik dengan alarm, penulisan pada papan kerja dengan tanda, atau saling mengingatkan antar sesama engineer di kapal.

\section{KESIMPULAN}

Penyebab kerja evaporator refrigerator menurun yaitu dikarenakan perawatan dan perbaikan pada komponenkomponen refrigerator tidak tepat waktu sehingga dapat menimbulkan masalahmasalah baru pada mesin. Terjadinya penumpukan bunga es pada pipa coil evaporator dikarenakan filter dryer yang sudah lama tidak diganti sehingga terjadi lolosnya kotoran dan air kedalam sistem.. Oil Separator tidak bekerja dengan baik dikarenakan laluan minyak lumas menuju ke ruang engkol tersumbat sehingga minyak lumas akan menumpuk dan seterusnya akan ikut kedalam sistem yang berdampak akan terjadi partikel-partikel di dalam pipa coil evaporator.
Agar dalam pengoperasian dan perawatan mesin pendingin berjalan dengan baik, sebaiknya masinis bertanggung jawab atas permesinan refrigerator, agar melakukan perawatan dan perbaikan tepat pada waktunya sesuai yang ada di manual book. Masinis dapat meningkatkan pengecekan pada dalam ruangan mesin pendingin, jika ada penumpukan bunga es segera melakukan defrosting dan setelah itu melakukan pergantian filter dryer selama 3 bulan sekali. Masinis sebaiknya juga melakukan pengecekan minyak lumas pada gelas duga, kalau minyak lumas menurun drastis maka langkah selanjutnya adalah untuk melakukan perawatan pada Oil Separator dan membersihkan lubang laluan di oil separator.

\section{DAFTAR PUSTAKA}

Berman, Ega Taqwali, 2013, Teknik Pendingin, Konsorsium Sertifikasi Guru, Jakarta.

Hartono, 2009, Faktor Penyebeb Tidak Tercapainya Suhu Kamar Pendingin Bahan Makanan Dikapal Mt. Dewi Sri, Semarang.

Jauhari, Lutfi, 2016, Bagian-Bagian Mesin Pendingin,

Sumanto, 2004, Dasar-Dasar Mesin Pendingin, PT. Andi Yogyakarta,Yogyakarta.

Manual Book, 2000, Ref. Provison Plant, Ushio Reinetsu Co., Ltd, Japan

Nasution, 2002, Metode Kuantitatif Kualitatif

Kaoru Ishikawa.www.dictio.id Teknik Analisis Fishbone

http://www.maritimeworld.web.id/2014/04/ bagian-bagian-mesin-pendinginrefrigerasi.html.

http://www.maritimeworld.web.id/2014/04/ bagian-bagian-mesin-pendinginrefrigerasi.html 